\title{
Pattern of chest diseases among addicts in Poison Control Center of Ain Shams University Hospitals
} Aya M. AbdelDayem ${ }^{\mathrm{a}}$, Mahmoud L. Sakr ${ }^{\mathrm{b}}$, Nehad M. Osman
Maryam A. Abd El Kader

Background Drug addiction results in serious pulmonary complications. Thoracic complications of drug addiction vary depending on the type and the route of administration of the drug that has been abused.

Aim To study the pattern of chest diseases among addicts in Poison Control Center of Ain Shams University Hospitals.

Patients and methods A total of 200 addict patients were selected from Poison Control Center of Ain Shams University Hospitals in the duration between June 2016 and June 2018. All patients with pulmonary complications referred to Abbasia Chest Hospital were included.

Results A total of 200 addict patients were enrolled in this study. Of them, 100 addicts with drug overdose with no pulmonary complications were excluded, and the other 100 patients were included, comprising 99 males and only one female, with mean age of $39.91 \pm 10.75$ years. Overall, $63 \%$ of drug addicts were cannabis addicts, $27.0 \%$ were opiate addicts, $8.0 \%$ were polysubstance abusers, and $2.0 \%$ were alcohol addicts. Pulmonary tuberculosis was the most common pulmonary complication of all drug addicts. There was a statistically significant correlation between the type of drug addiction and the pulmonary complications. Pulmonary tuberculosis was the most common among cannabis addicts as well as polysubstance abusers. Parenchymal lung

\section{Introduction}

Addiction is a brain disease, involving compulsive substance abuse; although substance abuse has harmful effects, there is continuous use of the substance, even if it will cause health problems. Drug addiction is treatable, and effective treatment helps people to recover from addiction and regain their lives [1].

Many different types of substances tend to be abused such as cannabinoids (cannabis), alcohol, stimulants (cocaine and nicotine), sedatives-hypnotics (barbiturates and benzodiazepine), narcotics (heroin and opium), and steroids [2].

Pulmonary vasculature is exposed to direct damage owing to injection and inhalation of illicit drugs. Pulmonary edema can occur with drug injection as it affects the pulmonary vascular permeability [3].

\section{Aim}

This study aimed to assess the pattern of chest diseases among addicts in Poison Control Center of Ain Shams University Hospitals. diseases (pneumonia and lung abscess) were the most common among opiate and intravenous drug addicts. There was no significant difference between different types of drugs and outcomes of the patients. Mortality represented $3.0 \%$ of all drug addicts.

Conclusion Many pulmonary complications are associated with drug addiction. Achievement of early diagnosis and treatment can be obtained by proper counseling and therapeutic programs.

Egypt J Bronchol 2019 13:704-709

(C) 2020 Egyptian Journal of Bronchology

Egyptian Journal of Bronchology 2019 13:704-709

Keywords: chest diseases, drug addiction, pulmonary complications

Departments of, a Chest Diseases, ${ }^{b}$ Clinical Toxicology, Faculty of Medicine, Ain Shams University, Cairo, Egypt, ${ }^{\circ}$ Professor of Chest Diseases, Faculty of Medicine, Ain Shams University, ${ }^{\mathrm{d} A s s i s t a n t ~ P r o f e s s o r ~ o f ~ C h e s t ~ D i s e a s e s, ~}$ Faculty of Medicine, Ain Shams University, ${ }^{\mathrm{e} A b b a s i a}$ Chest Hospital, Cairo, Egypt

Correspondence to Sherehan E. Abd El-Aaty, MSc, Nasr City, Cairo, 11717, Nasr City, Cairo, Egypt. Tel: +20 109948 5804; e-mail: sherehan_elsayed_shams@yahoo.com

Received: 16 July 2019 Accepted: 10 September 2019 Published: 21 January 2020

\section{Patients and methods}

This was a prospective cross-sectional study that was conducted on 200 addict patients in the duration between June 2016 and June 2018. All patients were selected from Poison Control Center of Ain Shams University Hospitals. All patients with pulmonary complications referred to Abbasia Chest Hospital were included.

Inclusion criteria were as follows: all addict patients who were at least 18 years, suspected to have pulmonary diseases and/or pulmonary complications, and agreed to participate in this study after taking a written consent (a written consent was taken from the patient himself or herself or relatives of first degree if the patient was disoriented).

The patients met the medical definition of addiction according to American Psychiatric Association,

This is an open access journal, and articles are distributed under the terms of the Creative Commons Attribution-NonCommercial-ShareAlike 4.0 License, which allows others to remix, tweak, and build upon the work non-commercially, as long as appropriate credit is given and the new creations are licensed under the identical terms. 
Diagnostic and Statistical Manual of Mental Disorders [4]. Addiction (termed substance dependence by the American Psychiatric Association) is defined as a maladaptive pattern of substance use leading to clinically significant impairment or distress, as manifested by three (or more) of the following, occurring any time in the same 12 -month period:

(1) Tolerance, as defined by either of the following:

(a) A need for markedly increased amounts of the substance to achieve intoxication or the desired effect.

(b) Markedly diminished effect with continued use of the same amount of the substance.

(2) Withdrawal, as manifested by either of the following:

(a) The characteristic withdrawal syndrome for the substance.

(b) The same (or closely related) substance is taken to relieve or avoid withdrawal symptoms.

(3) The substance is often taken in larger amounts or over a longer period than intended.

(4) There is a persistent desire or unsuccessful efforts to cut down or control substance use.

(5) A great deal of time is spent in activities necessary to obtain the substance (such as visiting multiple doctors or driving long distances), use the substance (e.g. chain-smoking), or recover from its effects.

(6) Important social, occupational, or recreational activities are given up or reduced because of substance use.

(7) The substance use is continued despite the knowledge of having a persistent physical or psychological problem that is likely to have been caused or exacerbated by the substance (e.g. current cocaine use despite recognition of cocaineinduced depression or continued drinking despite recognition that an ulcer was made worse by alcohol consumption).

All patients fulfilled at least three (or more) of these criteria, and then they meet the medical definition of addiction. This definition is based on the American Psychiatric Association.

\section{Exclusion criteria}

All patients who refused to participate in this study, patients with negative drug screen test, and all patients with drug overdose without any pulmonary complications were excluded.

All the patients were subjected to the following:

Full history taken including smoking index according to Nagata et al. [5]. The smoking index is a unit for measuring cigarettes consumption over a long period and was calculated using the following formula: smoking index=cigarettes/day $\times y e a r s$ of tobacco use. Smoking index categories were nonsmoker, mild less than 400 , moderate 400-799, and heavy of at least 800 .

History of drug addiction regarding the type of the drug, method and route of addiction, and psychiatric consultation.

Thorough clinical examination (general and local).

Radiological examination, including plain chest radiograph, posteroanterior view, computed tomography chest if indicated, chest ultrasound if indicated, echocardiography if indicated, and duplex if indicated (venous).

Laboratory examination: complete blood count, blood chemistry (including serum creatinine, blood urea nitrogen, and liver function tests, such as alanine transaminase and aspartate aminotransferase), arterial blood gases if indicated, and viral markers, including hepatitis B virus surface antigen, hepatitis C virus antibody, and HIV antibody.

Drug screen test: It was done using one-step drug screen test device (urine). This is a rapid screening test for the detection of drugs and drug metabolites in human urine at a certain concentration [6]. Different drugs were screened in urine according to addiction history taken from the patients (e.g. cannabis, tramadol, heroin and morphine).

Pulmonary function test, if possible: spirometer test result was according to Jeremy and Wesley [7]. Spirometer test result is based on the following:

$\mathrm{FVC} \geq \mathrm{LLN}$ and $\mathrm{FEV}_{1} / \mathrm{FVC}$ ratio $\geq \mathrm{LLN}$ or $\geq 70 \%$ diagnosis: normal.

FVC $\geq$ LLN and $\mathrm{FEV}_{1} / \mathrm{FVC}$ ratio $<\mathrm{LLN}$ or $<70 \%$ diagnosis: obstructive.

FVC $<$ LLN and $\mathrm{FEV}_{1} / \mathrm{FVC}$ ratio $\geq \mathrm{LLN}$ or $\geq 70 \%$ diagnosis: restrictive.

$\mathrm{FVC}<\mathrm{LLN}$ and $\mathrm{FEV}_{1} / \mathrm{FVC}$ ratio $<\mathrm{LLN}$ or $<70 \%$ diagnosis: mixed.

$\mathrm{FEV}_{1}=$ forced expiratory volume in $1 \mathrm{~s} ; \mathrm{FVC}=$ forced vital capacity; LLN=lower limit of normal.

Chronic obstructive pulmonary disease diagnosis was based on the presence of a postbronchodilator $\mathrm{FEV}_{1} /$ FVC, where less than $70 \%$ confirms the presence of persistent airflow limitation [8]. 
Quantitative culture was done if there were signs of infection. Sputum Ziehl-Neelsen stain was done for 3 successive days. GeneXpert (Cepheid, Sunnyvale, California, United States of America) of sputum was done if indicated.

Fiberoptic bronchoscopy workup was done if needed. Bronchoscopy was done according to British Thoracic Society guideline for diagnostic flexible bronchoscopy in adult [9].

\section{Statistical analysis}

Data were collected, tabled, and statistically analyzed using statistical package for the social sciences (SPSS version 15; International Business Machines Corporation (IBM), Chicago, Illinois, United States of America).

Parametric data were expressed as minimum, maximum, mean, and SD. Nonparametric data were expressed as number and percentage.

Comparison between two or more groups regarding nonparametric data was done using $\chi^{2}$.

Comparison between two groups regarding parametric data was done using unpaired $t$-test.

$P$ value was considered significant as follows:

$P$ value up to 0.05 was considered significant.

$P$ value up to 0.001 was considered as highly significant.

$P$ value more than 0.05 was considered insignificant.

\section{Ethical committee approval}

The study was done after ethical committee approval, and written consents were taken from the patients.

\section{Results}

A total of 200 addict patients were enrolled in this study. Of them, 100 addicts were excluded from the study with drug overdose with no pulmonary complications. The other 100 patients were included in the study, comprising 99 (99\%) males. The mean age was 39.91 \pm 10.75 years. Overall, $88.0 \%$ of patients were anemic. Mortality represents only $3.0 \%$ of all drug addicts. The most common drug addiction was cannabis (63.0\%), $27.0 \%$ were opiate addicts, $8.0 \%$ were polysubstance abusers (PSA), and 2.0\% were alcohol addicts. Inhalation was the most common route of drug administration among all routes of drug addiction (63.0\%). Comorbidities represent only $11.0 \%$ of all patients, with four diabetics and seven with hypertension (Table 1). The most common pulmonary complication of all drug addicts was pulmonary tuberculosis (TB) (36.0\%) and then parenchymal lung diseases (31.0\%) (Table 2).

There was a significant correlation between the type of drug addiction and the pulmonary complications of the studied patients. Pulmonary TB was the most common among cannabis addicts (44.5\%) as well as PSA (50.0\%). Among opiate addicts, parenchymal lung diseases were the most common (48.0\%) (Table 3).

There was also a significant correlation between the route of drug addiction and the pulmonary complications of the studied patients. Pulmonary TB was the most common among inhalational drug addicts

Table 1 Description of the different types of drug addiction, the route of administrations and comorbidities of the studied patients

\begin{tabular}{lc}
\hline & $N=100[n(\%) / n / N(\%)]$ \\
\hline Drug type & $63(63.0)$ \\
Cannabis & $27(27.0)$ \\
Opiates & $16 / 27(59.3)$ \\
Morphine & $7 / 27(25.9)$ \\
Tramadol & $4 / 27(14.8)$ \\
Heroin & $8(8.0)$ \\
Polysubstance & $2(2.0)$ \\
Alcohol & \\
Route of drug addiction & $63(63.0)$ \\
Inhalation & $20(20.0)$ \\
Intravenous & $9(9.0)$ \\
Oral & $8(8.0)$ \\
Mixed & \\
Comorbidity & $89(89.0)$ \\
No & $4(4.0)$ \\
Hypertension & $7(7.0)$ \\
Diabetes mellitus & \\
\hline
\end{tabular}

Table 2 Description of the pulmonary complications of the studied patient

\begin{tabular}{lc}
\hline & $N=100$ \\
{$[n(\%) / n / N(\%)]$} \\
\hline Airway disease & $20(20.0)$ \\
Bronchitis & $2 / 20(10.0)$ \\
Chronic obstructive pulmonary disease & $18 / 20(90.0)$ \\
Pulmonary tuberculosis & $36(36.0)$ \\
Parenchymal disease & $31(31.0)$ \\
Abscess & $13 / 31(42.0)$ \\
Acute respiratory distress syndrome & $1 / 31(3.2)$ \\
Pneumonia & $16 / 31(51.6)$ \\
Pulmonary edema & $1 / 31(3.2)$ \\
Malignancy & $3(3.0)$ \\
Bronchogenic carcinoma & $3 / 3(100)$ \\
Pleural disease & $10(10)$ \\
Empyema & $3 / 10(30.0)$ \\
Pneumothorax & $6 / 10(60.0)$ \\
Tuberculous effusion & $1 / 10(10.0)$ \\
\hline
\end{tabular}


(44.5) as well as mixed drug addicts (50.0\%). Parenchymal lung diseases were the most common among intravenous drug addicts (65.0\%), and among oral drug addicts, airway diseases were the most common (77.8\%). All the patients with malignancy were inhalational drug addicts (cannabis) (Table 4).

There was no significant difference between different routes of drug addiction and outcome of the patients $(P=0.3)$.

\section{Discussion}

Drug addiction commonly causes many pulmonary complications. The lungs are affected with the different routes of drug addiction, as inhaled or injected drugs can damage and destroy the lungs. Awareness of the pulmonary complications of drug addiction by physicians is very important for correct diagnosis and management [3].

This study was conducted on 200 addict patients. Of them, 100 addicts with drug overdose with no pulmonary complication were excluded, and the other 100 patients comprising $99.0 \%$ males were included. Overall, 88.0\% were anemic. This finding agrees with Dogar et al. [10] who studied association between drug dependence and anemia in 64 drugdependent cases in Pakistan. It was found that all patients were males and $89 \%$ of them had anemia. Domination of the male sex among the included patients may be attributed to the habits and traditions of our society and owing to the fact that most of female patients in our country find it shameful to seek medical advice because of addiction, and also men have easier accessibility to drugs.

In this study, the most commonly abused drug was cannabis (63.0\%), and inhalation was the most common route of administration of abused drugs. This coincides with Saeed et al. [11] who studied the respiratory problems upon addict patients at Abbasia Chest Hospital. They found that cannabis is the most commonly abused drug (67.0\%), and inhalation represents $67 \%$ of all routes of drug addiction. On the contrary, Askarian et al. [12], who studied TB among 319 never-jailed drug abusers in Iran, found that injection drug abusers were the most common among cases (52.0\%), and those who inhaled substances represented only $28.0 \%$. This difference can be explained by that cannabis is more easier to be used in our society as a smoking habit and has lower cost than intravenous drugs.

In this study, pulmonary TB was the most common pulmonary complication, accounting for $36.0 \%$, and then parenchymal lung diseases [pneumonia, abscess, and acute respiratory distress syndrome (ARDS)], accounting for $31 \%$. This was in agreement with Saeed et al. [11] who found that the prevalence of pulmonary TB was $35.8 \%$ of all drug addict cases and

Table 3 Relation between different types of drug addiction and the pulmonary complications

\begin{tabular}{|c|c|c|c|c|c|}
\hline & $\begin{array}{l}\text { Airway disease } \\
(n=20)[n(\%)]\end{array}$ & $\begin{array}{l}\text { Tuberculosis } \\
(n=35)[n(\%)]\end{array}$ & $\begin{array}{l}\text { Parenchymal disease } \\
\qquad(n=30)[n(\%)]\end{array}$ & $\begin{array}{c}\text { Malignancy }(n=3) \\
{[n(\%)]}\end{array}$ & $\begin{array}{l}\text { Pleural disease } \\
(n=10)[n(\%)]\end{array}$ \\
\hline Cannabis $(n=63)$ & $11(17.5)$ & $28(44.5)$ & $15(23.8)$ & $3(4.7)$ & $6(9.5)$ \\
\hline Opiates $(n=27)$ & $9(33.5)$ & $3(11.0)$ & $13(48.0)$ & 0 & $2(7.5)$ \\
\hline $\begin{array}{l}\text { Polysubstance } \\
\text { abusers }(n=8)\end{array}$ & 0 & $4(50.0)$ & $2(25.0)$ & 0 & $2(25.0)$ \\
\hline$\chi^{2}$ & & & 17.8 & & \\
\hline$P$ & & & $0.02^{*}$ & & \\
\hline
\end{tabular}

$P<0.05$, significant. $P<0.001$, highly significant. $P>0.05$, insignificant. ${ }^{\star} P$ value is significant $(P<0.05)$.

Table 4 Relation between different routes of drug addiction and the pulmonary complications

\begin{tabular}{|c|c|c|c|c|c|}
\hline & $\begin{array}{c}\text { Airway disease }(n=20) \\
{[n(\%)]}\end{array}$ & $\begin{array}{c}\text { Tuberculosis }(n=36) \\
{[n(\%)]}\end{array}$ & $\begin{array}{l}\text { Parenchymal disease } \\
\quad(n=31)[n(\%)]\end{array}$ & $\begin{array}{c}\text { Malignancy }(n=3) \\
{[n(\%)]}\end{array}$ & $\begin{array}{l}\text { Pleural disease } \\
(n=10)[n(\%)]\end{array}$ \\
\hline $\begin{array}{l}\text { Inhalation } \\
(n=63)\end{array}$ & $11(17.5)$ & $28(44.5)$ & $15(23.8)$ & $3(4.7)$ & $6(9.5)$ \\
\hline $\begin{array}{l}\text { Intravenous } \\
(n=20)\end{array}$ & $2(10.0)$ & $3(15.0)$ & $13(65.0)$ & 0 & $2(10.0)$ \\
\hline Oral $(n=9)$ & 7 (77.8) & $1(11.1)$ & $1(11.1)$ & 0 & 0 \\
\hline Mixed $(n=8)$ & 0 & $4(50.0)$ & $2(25.0)$ & 0 & $2(25.0)$ \\
\hline$\chi^{2}$ & & & 37.7 & & \\
\hline$P$ & & & $0.0001^{* *}$ & & \\
\hline
\end{tabular}

$P<0.05$, significant. $P<0.001$, highly significant. $P>0.05$, insignificant. ${ }^{\star *} P$ value is highly significant $(P<0.001)$. 
parenchymal lung diseases accounted for $25.7 \%$. This is inconsistent with Askarian et al. [12] who found that the prevalence rate of pulmonary TB among drug abusers was $2.5 \%$. This difference and high percentage of $\mathrm{TB}$ in our study may be attributed to that pulmonary $\mathrm{TB}$ is epidemic in our country, and social and environmental factors such as limited ventilation, overcrowding, lifestyle, and lack of routine medical care of drug addicts in Egypt delay diagnosis. As the disease progresses, patients tend to become more contagious and consequently more infectious.

In this study, the most common pulmonary complication among cannabis addicts (inhalational drug addicts) was TB (44.4\%). Similar result were demonstrated by Saeed et al. [11] who found that TB was the most common pulmonary complication among cannabis addicts and inhalational drug addicts (37.0 and $38.2 \%$, respectively) and also was matched with Sterling et al. [13] who described TB outbreak among a highly mobile population in Baltimore, Maryland. It was found that frequent marijuana use has been reported among TB outbreak patients. On the contrary, Mathur and Chaudhary [14], who studied the increased risk of TB in 124 opium addicts in India, found that all the 124 opium addicts were taking treatment for pulmonary TB. In cases with opium addicts, the addiction always preceded pulmonary TB. This difference may be owing to that their study was only on opium addicts.

The most common pulmonary complication among opiate addicts and intravenous drug addicts was parenchymal lung diseases $(48.0$ and $65 \%$, respectively). Therefore, the results of the present study are similar to the result of Saeed et al. [11] who found that the most common pulmonary complication among opiate addicts and intravenous drug abusers was parenchymal diseases (35.7 and 36.8\%, respectively). This was against Farrag et al. [15] who studied the pulmonary manifestations and outcome of intravenous drug users admitted to Abbasia Chest Hospital. It was found that pleural diseases were the most common and accounted for 51.0\%. This difference may be owing to that their study was on intravenous drug abusers only.

In this study, the most common pulmonary complication among PSA (mixed drug addicts) was TB at 50\% (4/8). This coincides with Saeed et al. [11] who found that TB was the most common among PSA (43.7\%). In contrast to our study, Saeed et al. [16], who studied respiratory complications of addiction among
60 patients at Mansoura Chest Hospital, found that the most common complication among PSA was chronic obstructive pulmonary disease. This difference may be owing to that most of the patients in their study were PSA (55\%) and most of them were taking opioids in combination with cannabinoid; therefore, airway diseases (55\%) were the most common. However, in our study, PSA represent only $8.0 \%$.In this study, the most common pulmonary complication among oral drug addicts was airway diseases (77.7\%). This is similar to the study done by Saeed et al. [17], who studied the pulmonary complications among 66 addicts admitted to different Departments and ICUs of Ain Shams University Hospitals. It was found that the most common pulmonary complication among oral drug addicts was airway diseases. This was not in accordance with Saeed et al. [11], who found that the most common pulmonary complication among oral addicts was parenchymal lung diseases (36.4\%). This difference may be owing to the effect of smoking in our patients and small sample size of oral addicts in our study, with only nine patients.

All the patients with malignancy (100\%) were cannabis addicts (inhalation route) (bronchogenic carcinoma). This is similar to the study done by Saeed et al. [11] who found that $83 \%$ of malignancy cases among drug addicts were cannabis addicts (inhalational route). On the contrary, Mehra et al. [18] in a systematic review in 2006 studied the effect of marijuana smoking on lung premalignant findings and lung cancer from 1966 to the second week of October 2005, involving persons 18 years or older who smoked marijuana, and examined for premalignant or cancerous changes in the lung. They concluded that that there were no data showing an association of marijuana smoking with lung cancer. This difference may be owing to the duration difference between both studies and the numbers of patients.

There were some limitations we faced in this study, such as the refusal of many addicts to participate in the study for fear of being subjected to legal punishment or to inform their workplaces or relatives of their problem of addiction. There were limited number of addicts with pulmonary complications, as the most of addicts in Poison Control Center presented with drug overdose and toxicity.

\section{Conclusion}

Many pulmonary complications are associated with drug addiction. Achievement of early diagnosis and 
treatment could be obtained through proper counseling and therapeutic programs.

\section{Financial support and sponsorship}

Nil.

\section{Conflicts of interest}

There are no conflicts of interest.

\section{References}

1 Ranna P. Addiction and substance use disorders. Washington: American Psychiatric Association. 2017

2 Vivek B. Psychoactive substances/substance abuse/drug abuse 2014 Medically reviewed by Dr Reeja Tharu on 12 April 2018. https://www. medindia.net/patients/patientinfo/drugabuse.htm. [Accessed 20 May 2018].

3 Yogiaveetil E, O'Donnell A. Pulmonary complications of illicit drug use 2019. Pulmonology Advisor, https://www.infectiousdiseaseadvisor.com/ pulmonary-medicine/pPulmonary-complications-of-illicit-drug-use/article/ 625573/. [Accessed 10 February 2018].

4 American Psychiatric Association. DSM-IV Substance Dependence Criteria. Diagnostic and statistical manual of mental disorders. Fourth edition. Washington, DC: American Psychiatric Association. 2000.

5 Nagata N, Niikura R, Shimbo T, Kishida Y, Sekine K, Tanaka S, et al. Alcohol and smoking affect risk of uncomplicated colonic diverticulosis in Japan. PLoS One 2013; 8:e81137.

6 Tietz NW. Textbook of clinical chemistry. Philadelphia: W.B. Saunders Company. 1986. p. 1735.

7 Johnson JD, Theurer WM. A stepwise approach to the interpretation of pulmonary function tests. Am Fam Physician 2014; 89:359-366.
8 Global Initiative for Chronic Obstructive Lung Disease (GOLD): POCKETGUIDE-V1. 7. Available at: https://goldcopd.org/wp-content/uploads/2018/ 11/GOLD-2019-POCKET-GUIDE-DRAFT-v1.7-14Nov2018-WMS.pdf. [Accessed 14 November 2018]

9 Du Rand IA, Blaikley J, Booton R, Chaudhuri N, Gupta V, Khalid S, et al. on behalf of the British Thoracic Society Bronchoscopy Guideline Group. Thorax 2013; 68:i1-:i44.

10 Dogar IA, Sulheri MA, Ali MS. Association between drug dependence and anemia in Pakistani patients. APMC 2007; 1:9-13.

11 Saeed AM, Riad NM, Kamel MN. Study of respiratory problems of addiction among patients at Abbasia Chest Hospital. 2011 (unpublished master dissertation). Ain Shams University, Cairo, Egypt.

12 Askarian M, Karmi A, Sadeghi-Hassanabadi A. Tuberculosis among never-jailed drug abusers. East Mediterr Health $J 2001$ 7:461-464.

13 Sterling TR, Thompson D, Stanley RL, McElroy PD, Madison A, Moore K, et al. A multi-state outbreak of tuberculosis among members of a highly mobile social network: implications for tuberculosis elimination. Int $J$ Tuberc Lung Dis 2000; 4:1066-1073.

14 Mathur ML, Chaudhary RC. Increased risk of tuberculosis in opium addicts. Indian J Med Sci 1996; 50:365-367.

15 Farrag MA, Mohamed RM, Ali KM. Pulmonary manifestation and outcome of intravenous drug users admitted to Abassia Chest Hospital. 2018 (unpublished master dissertation). Ain Shams University, Cairo, Egypt.

16 Saeed AM, Mohamed H, El-Saeed DY. Respiratory complication of addiction among patients at Mansoura Chest Hospital. 2017 (unpublished master dissertation). Ain Shams University, Cairo, Egypt.

17 Saeed AM, Salem HM, El Ghannam AA. Study of respiratory complications of addiction among patients at Ain Shams University Hospitals. 2011 (unpublished master dissertation). Ain Shams University, Cairo, Egypt.

18 Mehra R, Moore BA, Crothers K, Tetrault J, Fiellin DA. The association between marijuana smoking and lung cancer: a systematic review. Arch Intern Med 2006; 166:1359-1367. 